\title{
Participación sociopolítica y democratización
}

Uno de los rasgos más notorios de la década de los años noventa son los bajos niveles organizativos y la limitada participación de la sociedad civil en la escena pública, sobre todo si esta década es comparada con la década de los años setenta, cuando se generó un intenso proceso de organización y participación popular ${ }^{1}$.

A principios de los años setenta, surgieron las organizaciones Federación Cristiana de Campesinos Salvadoreños (FECCAS) y la Unión de Trabajadores del Campo (UTC) -que luego se aglutinaron en la Federación de Trabajadores del Campo (FTC) - , las cuales desempeñaron una función relevante como canales de expresión de las demandas de la población rural del país. Lentamente esas demandas fueron trascendiendo lo meramente reivindicativo hasta plantearse objetivos estrictamente políticos. En un comunicado de FECCAS se dice lo siguiente: “nuestra organización de ninguna manera puede quedarse en la lucha por las demandas inmediatas, que es una lucha por la subsistencia. Con ella no se alcanzará el fin de la explotación ni se resolverán, en consecuencia, los problemas fundamentales de los trabajadores del campo. Para terminar definitivamente con la explotación capitalista, FECCAS plantea la urgente necesidad de que los jornaleros y campesinos pobres se incorporen a la Lucha Revolucionaria, objetivo que se alcanzará ligando correctamente la lucha por las necesidades inmediatas a la lucha por las necesidades fundamentales"'

En 1975, surge el Bloque Popular Revolucionario (BPR), que aglutina tanto a FECCAS-UTC - ya articuladas en la FTC - , como a los maestros afiliados a ANDES 21 de junio, los estudiantes de secundaria y universitarios organizados en el Movimiento Estudiantil de Revolucionario de Secundaria (MERS), Universitarios Revolucionarios 19 de julio (UR-19) y Frente Universitario Revolucionario 30 de junio (FUR-30), a los pobladores de tugurios vinculados a la UPT, el Movimiento de Cultura Popular (MLP), los Comités de Barrios y Colonias (CBC) y el Comité de Señoras de los Mercados (CSM). Según Carlos Rafael Cabarrús, la formación del BPR, como frente popular de masas, "aseguraba al movimiento miras más amplias y aporte teórico distinto, pero enraizado en las masas campesinas, prestas a desfilar por las calles de San Salvador, conscientes de su fuerza y sabiendo que se puede nadar contra la corriente cuando el río es todavía pequeño, pero nadie puede lograrlo cuando se vuelve poderoso"'. En un comunicado del BPR -en el que la organización se solidariza con la iglesia católica y la Compañía de Jesús - se puede leer lo siguiente: "el Bloque Popular Revolucionario aglutina en su seno a Organizaciones Populares de la

1. En la década de los años setenta existicron otras organizaciones que no tuvicron mayor rclcvancia política. Dos de ellas fueron la Liga Obrera Revolucionaria, que se decía afín a la IV Internacional - heredera de León Trotski, y que estaba comprometida con la creación de un "frente único proletario"-, y el Grupo Socialista Internacionalista, también simpatizante de la IV Internacional

2. Documento interno de FECCAS, citado por C. R. Cabarrús, Génesis de una revolución. Análisis del surgimiento de la organización campesina en El Salvador, México, Casa Chata, 1983.

3. C. R. Cabarrús, Génesis... p. 163. 
clase explotada y, como tal, promueve las reivindicaciones inmediatas y fundamentales del trabajador, luchando constantemente por la dignificación del hombre". El pronunciamiento, como otros difundidos en la época, finaliza con el siguiente lema: "iiFrente a la agresión fascistoide, el combate organizado del pueblo!!"4.

Un año antes, en 1974, se había constituido el Frente de Acción Popular Unificada (FAPU), el cual estaba formado por el Movimiento Revolucionario Campesino (MRC), Vanguardia Proletaria (VP), Unión Nacional de Jornaleros (UNJ), Asociación Revolucionaria de Estudiantes de Secundaria (ARDES), Organización Magisterial Revolucionaria (OMR), Frente Universitario de Estudiantes Revolucionarios "Salvador Allende" (FUERSA) y Comité de Vecinos y Cristianos. En un documento de la organización se dice lo siguiente: "el nacimiento del FAPU, al plantear una diferente concepción de política frentista, indicó la forma histórica que correspondería impulsar para este período. Después del FAPU han surgido diversas propuestas frentistas (carentes unas de fundamentos ideológicos proletarios, partiendo otras de planteamientos meramente organicistas y ninguna con un correcto análisis e interpretación del actual período que vivimos) todas las cuales lejos de debilitar nuestros planteamientos, han seguido nuestro señalamiento y con ello nos confirman como la posición de avanzada ante las masas, en relación a las formas de organización popular que exige el actual estado de la lucha por la liberación" . Asimismo, uno de los lemas con los que el FAPU solía terminar sus comunicados decía lo siguiente: “¡¡Organizar, combatir y vencer por la clase obrera y por el pueblo!!".
En 1977, en el marco del fraude electoral que llevó al poder al general Carlos Humberto Romero $^{6}$, surgen las Ligas Populares 28 de Febrero (LP28), formadas por las Ligas Populares Campesinas (LPC), Ligas Populares Estudiantiles de Secundaria (LPES), Ligas Populares Obreras (LPO), Ligas Populares Universitarias y las vendedoras de los mercados afiliadas a ASUTRAMES. En un documento intemo de las LP-28 se plantean los siguientes tópicos como lineamientos políticos de la organización: "( $a$ ) para el pueblo salvadoreño y para las masas trabajadoras, el elemento fundamental es la organización y preparación que las capacite para alcanzar y respaldar sus conquistas democráticas. Debemos basarnos en nuestros propios esfuerzos y capacidad para garantizar nuestros logros e intereses profundizando la organización política y haciendo avanzar la claridad de conciencia en la lucha por los objetivos fundamentales de la clase trabajadora; (b) el objetivo de 'LAS LIGAS POPULARES 28 DE FEBRERO' no es rivalizar en la lucha por la supremacía política, sino la búsqueda del fortalecimiento del movimiento popular y democrático a través de un proceso de acercamiento, entendimiento y coordinación con el resto de fuerzas políticas que nos lleve a confluir en el necesario proceso de unidad a través de un FRENTE AMPLIO DEMOCRÁTICO contra la dictadura; (c) integrarse a una situación histórica trascendental, en la que es posible alcanzar verdaderas conquistas democrálicas del pueblo salvadoreño a partir de derrolar al régimen fascista y su demagógica apertura. Conquistas que serán los primeros pasos de las masas trabajadoras en su preparación para alcanzar el logro de sus intereses fundamentales"?

En 1979, se funda el Movimiento de Liberación Popular (MLP), integrado por los Comités de

4. Bloque Popular Revolucionario, “Solidaridad con la Iglesia Calólica y la Compañia de Jesús", La Prensa Gráfica, jueves 7 de julio de 1977. En algunos comunicados se solía añadir, al anterior lema, lo siguiente: “¡iPor la revolución popular. Hacia el socialismo!!".

5. “¿Qué es el FAPU?”, Liberación, órgano de divulgación política del Frente de Estudiantes Universitarios Revolucionarios "Salvador Allende", San Salvador, s.f., p. 13.

6. Como es sabido, en esa coyuntura electoral la alianza política perdedora fue la Unión Nacional Opositora (UNO), que llevaba al coronel Ernesto Claramount y a Antonio Morales Erlich como candidatos a la presidencia y a la vicepresidencia, respectivamente. Ahora bien, la UNO no era bien vista por organizaciones como el Bloque Popular Revolucionario. En efecto, para este frente de masas, la UNO es "una alianza de partidos burgueses y pequeño burgueses y el revisionismo de derecha (PDC, MNR y UDN, respectivamente) el cual ambiciona, como en las anteriores coyunturas, el poder burgués del Estado para dominar al pueblo y fortalecer el sistema de explotación capitalista a través de una democracia representativa", Combate popular, órgano político-ideológico del Bloque Popular Revolucionario, 1, febrero de 1977, p. 1.

7. "Las Ligas Populares 28 de febrero llaman al movimiento democrático y popular a luchar unidos contra la dictadura", s.f. 
Bases Obreras, las Brigadas Revolucionarias de Estudiantes de Secundaria (BRES), Brigadas de Trabajadores del Campo (BTC), Brigadas Obreras (BO) y Liga para la Liberación (LL). Del congreso constituyente del MLP, celebrado en diciembre de 1979 , surgió un documento en el que se plasmaron las tesis programáticas básicas de la organización, denominadas "programa mínimo revolucionario", el cual "debe ser completamente realizable a partir de las relaciones de producción existentes y al nivel de las fuerzas productivas" y "debe sentar las bases para la edificación de la nueva sociedad, libre de la explotación del hombre por el hombre"s. El documento finaliza con el siguiente lema: "Por la construcción de una nueva sociedad con el poder popular orientado por un programa revolucionario. Luchar hasta vencer por la liberación popular".

En su conjunto, esos frentes de masas" alcanzaron a incorporar a sus filas aproximadamente unas 150 mil personas ${ }^{10}$, dispuestas a participar en movilizaciones de calle, protestas, huelgas, paros laborales, tomas de edificios públicos, embajadas, iglesias y propiedades rurales. La historia reciente del país no ha conocido una fase más intensa de participación social masiva que la de esa década. A principios de 1980 , la represión estatal se agudizó sobre esas organizaciones populares, siendo violentamente desmembradas; los asesinatos, las torturas, las desapariciones y la persecución sistemáticas estuvieron a la orden del día.

En 1981, la Comisión Interamericana de Derechos Humanos, en su Informe a la Asamblea General, escribió lo siguiente: "durante el período al que se contrae este informe, las violaciones más graves de derechos humanos se manifestaron, en relación al derecho de vida, a través de ejecuciones ilegales. Tales ejecuciones ocurrieron principalmente, aunque no exclusivamente, en El Salvador y Guatemala. Dentro del clima de violencia generalizada que sacude a estos dos países acaecieron, en una cantidad verdaderamente alarmante, lo que la Comisión ha convenido en llamar ejecuciones ilegales o extrajudiciales. Tales ejecuciones, la mayoría de las veces, fueron cometidas por las fuerzas de seguridad que actúan impunemente al margen de la ley, como asimismo por grupos paramilitares que obran con la aquiescencia o consentimiento tácito de los gobiemos... El fenómeno de las ejecuciones ilegales suele también venir acompañado de lamentables circunstancias agravantes. En ocasiones, los cadáveres descubiertos presentan brutales señales de tortura. Muchas veces los cuerpos se encuentran desnudos, sin identificación, algunas veces incinerados, las mujeres por lo general violadas $y$, en fin, las personas dejan huellas de haber sido objeto de innumerables apremios que seguramente han sido la causa directa de su muerte"

Cuando se desata la guerra civil, con la "ofensiva general" de enero de 1981, los frentes de masas inician un proceso de desarticulación que llevó a su extinción. Quienes no fueron asesinados o desaparecidos salieron huyendo del país con rumbo a Honduras, México, Estados Unidos, Canadá y Australia. Otros, los que se quedaron en el país, se incorporaron al FMLN como combatientes o como base social de apoyo. Durante la primera fase de la guerra civil -1981-1982 - los movimientos sociales y la organización de la sociedad civil estuvieron apagados. El temor a la represión estatal era el principal impedimento para ello. En 1983 se inició un lento resurgir del movimiento social, especialmente de las organizaciones sindicales. El escenario de la movilización laboral, como señala Rafael Guidos Véjar, "se amplió con el sector estatal y los movilizadores son, también, los trabajadores del sector público (gobierno central y municipal, instituciones oficiales descentralizadas, nacionalizadas, etc.)"12 .

A mediados de la década afloraron dos organizaciones que apuntaban a un resurgimiento del movimiento social: la Unión Nacional de Trabaja-

8. Movimiento de Liberación Popular, Programa mínimo revolucionario, San Salvador, diciembre de 1979, p. 3.

9. La Unión Democrática Nacionalista (UDN), fachada legal del Partido Comunista Salvadoreño (PCS), también quiso asumir un esquema de frente de masas - a partir del respaldo de su base sindical一, aunque sin lograrlo del todo, debido a su cstructura de partido político.

10. Ver S. Montes, El Salvador: las fuerzas sociales en la presente coyuntura (enero 1980 a diciembre 1983), San Salvador, Universidad Centroamericana "José Simeón Cañas", 1984.

11. Informe anual de la Comisión Interamericana de Derechos Humanos de la Asamblea General de la OEA, 1981.

12. R. Guidos Béjar, "El movimiento sindical después de la segunda guerra mundial en El Salvador", ECA, 504, octubre de 1990, pp. 882-883. 
dores Salvadoreños (UNTS) y la Unión Nacional Obrero Campesina (UNOC) ${ }^{13}$. Sin embargo, la polarización sociopolítica era tal, que ambas organizaciones terminaron plegándose - con la subsiguiente pérdida de autonomía - a los dos bandos en pugna: la UNTS se vio influenciada por el FMLN y la UNOC por el gobiemo demócrata cristiano. En efecto, "en su posición crítica al ejecutivo, la UNTS convoca a sectores del Estado en manos de la oposición, a los partidos políticos opositores, a grupos de sectores sociales afectados por la crisis, etc., y constituye una plataforma de masas que contiene no sólo demandas de fábrica, sino también políticas públicas nacionales (...) y propuestas para la conducción gubernamental... La IADSL y el gobiemo reaccionaron en contra de la UNTS (...), organizando sindicatos paralelos en los lugares de trabajo, organismos de unidad competitivos a la UNTS (como la UNOC) y trabajando para desintegrarla orgánicamente"14.

Asimismo, desde mediados de la década de 1980 comenzaron a proliferar una serie de organizaciones no gubernamentales, las cuales no pudieron sustraerse al clima de polarización político-militar prevaleciente; con ello, su autonomía se vio sensiblemente afectada y sus objetivos muchas veces fueron enturbiados por los intereses políticomilitares prevalecientes.

De este modo, la situación de los agrupamientos sociales, las asociaciones voluntarias y los movimientos sociales en el momento actual no puede entenderse sin el trasfondo de lo sucedido en las dos décadas precedentes. En la década de los años noventa, son escasas las asociaciones voluntarias y los grupos de ciudadanos. De las primeras, la gran mayoría de las que existen - de escultismo, de salvamento, de lucha contra las drogas, deportivas- guardan una relación de afinidad con el gobierno. De las segundas, la gran mayoría de las que se forman - directivas comunales o directivas escolares - o bien tienen una vida efímera o bien son puramente decorativas. Mientras tanto, en la presente década, los movimientos sociales que se han gestado no han logrado consolidarse, sostenerse en el tiempo o trascender a propósitos de lucha socialmente más amplios. Un buen ejemplo de ello son las protestas de los desmovilizados de la Fuerza Armada o el movimiento huelguístico impulsado por los médicos del sistema de salud pública.

No cabe duda de que el nivel de participación ciudadana en asociaciones voluntarias y organizaciones autónomas es sumamente reducido. Por un lado, las asociaciones voluntarias y las organizaciones autónomas son escasas. Por otro, la motivación ciudadana para integrarse a las mismas es casi inexistente. De hecho, es este factor el que explica, en buena medida, no sólo el poco número de organizaciones y asociaciones, sino los bajos niveles de afiliación que las caracterizan. Y eso es así incluso en asociaciones y organizaciones de empleados y profesionales. Para mencionar sólo a un par de ellas, asociaciones como la de los empleados de la Corte de Cuentas (ADECC) y el Colegio de Profesionales en Ciencias Económicas (COLPROCE), ni aglutinan a todos aquellos que dicen servir ni tienen una presencia decisiva en sus ámbitos de influencia respectivos. Lo mismo puede decirse de asociaciones de empleados y cooperativas que surgen en universidades, instituciones bancarias y fábricas. Otras asociaciones como las de Boy Scout, de Salvamento (Cruz Roja y la Cruz Verde), de prevención en el uso de las drogas (FUNDASALVA), clubes rolarios (Club de Leones) y deportivas (los diferentes clubes de Fútbol) cuentan con un número reducido de miembros y su influjo social es bastante limitado.

Asimismo, también los niveles de participación en actividades públicas voluntarias son sumamente bajos. Quizás las actividades religiosas son las que tienen mayor poder de convocatoria ciudadana; aunque no todas las actividades religiosas movilizan a igual número de ciudadanos. Así, en la década de los años noventa, se han gestado dos celebraciones religiosas que involucran a un número significativo de salvadoreños en una actividad de carácter público: las celebraciones del aniversario del asesinato de Mons. Óscar Romero (24 de marzo) y las celebraciones del aniversario del asesinato de los jesuitas de la UCA (16 de noviembre). Luego, otro foco de participación pública voluntaria, siempre con motivación religiosa, lo constituyen las fiestas dedicadas a los santos y patronos de

13. Ver M. Lungo, La lucha de masas en El Salvador, San Salvador, UCA Editores, 1987.

14. R. Guidos Béjar, ibid., p. 884. 
barrios, colonias y municipios. $\mathrm{Y}$, en tercer lugar, están las actividades deportivas - torneos comunitarios, de barrio o intercoloniales-, los cuales cada vez más cuentan con menos participación de los habitantes urbanos del país.

Otras formas de participación en actividades públicas voluntarias que no sean religiosas o deportivas son algo esporádico y casi de carácter excepcional. Un buen ejemplo de ello lo constituyen las reuniones de vecinos en las zonas urbanas: por lo general, esas reuniones se realizan para responder a problemas específicos de los vecinos - vigilancia, recolección de basura, alumbrado público-, tras cuya solución no vuelven a repetirse.

Lo anterior tiene que ver con una tendencia que viene imponiéndose en la dinámica de los comportamientos sociales en la presente década: la tendencia hacia la privatización de las actividades familiares y personales. Esto tiene como contrapartida no sólo una "retirada" del espacio público -compromisos colectivos, tareas comunitarias, desafíos comunitarios -, sino una privatización de actividades familiares y personales que solían tener un fuerte sentido social: fiestas de cumpleaños, fiestas de navidad, parrilladas con los vecinos, etc. La violencia delincuencial -que obliga encerrarse tras las paredes del hogar-, la tecnología -que hace de ese encierro algo agradable - y la insatisfacción con la política y los políticos -que desalientan el compromiso ciudadano- refuerzan la tendencia hacia la privatización de las prácticas sociales, es decir, la renuncia ciudadana a participar en actividades públicas.

Por otra parte, las mujeres con todo y ser porcentualmente mayoría demográfica, tienen una reducida participación en la vida política nacional. En su mayor parte, los partidos -organizaciones que son, por definición, canales de participación ciudadana- no sólo están dominados en su composición interna por hombres, sino que son éstos quienes concentran en sus manos las decisiones partidarias más importantes, lo cual es posible por su papel como dirigentes políticos. Algunos partidos fomentan más que otros la participación de las mujeres.

Así, ARENA y el FMLN cuentan entre sus filas con un importante sector femenino, a través del cual se canaliza su participación tanto en su interior como en la vida política nacional. No obstante, tanto en ARENA como en el FMLN la mayor



parte de integrantes son hombres; asimismo, los principales cargos de dirección partidaria están en manos de éstos. En lo que se refiere a los demás partidos - Partido de Conciliación Nacional, Partido Demócrata Cristiano, Centro Democrático Unido, PAN-, la situación es más crítica para las mujeres: estos partidos, aunque cuentan entre sus filas con militantes mujeres, nos las han incorporado en un número suficiente como para pesar en las decisiones partidarias o poder acceder a puestos de dirección institucional. En El Salvador, pues, los partidos políticos están dominados en su composición por los hombres y son dirigidos por éstos. Ello merma sensiblemente las posibilidades de participación política de las mujeres, las cuales no encuentran en los partidos ni un espacio propio para defender sus intereses ni un clima favorable —dados los prejuicios machistas prevalecientes entre los miembros de los partidos- para discutir, en igualdad de condiciones, con los hombres los problemas nacionales desde su propia perspectiva.

En la misma línea, el acceso de las mujeres a cargos de dirección partidaria es sumamente difí- 
cil, incluso en aquellos partidos con un sector femenino fuerte y con una política de selección de liderazgos femeninos. Las mujeres no sólo tienen que competir con las habilidades y capacidades de los hombres -muchas veces inferiores a las suyas-, sino con esquemas culturales que, por principio, dan por descontada la superioridad de éstos sobre aquéllas. Una vez que determinadas mujeres han logrado el acceso a un cargo de dirección, han sido objeto de evaluaciones permanentes de los hombres - muchas veces compañeros de partido subordinados a ellas-, así como de comentarios y críticas en voz baja acerca de sus limitaciones y deficiencias, atribuidas a su naturaleza femenina.

También las mujeres han tenido que soportar y aceptar los comentarios sexistas y las expresiones con doble sentido - en uno de los cuales la mujer suele aparecer como objeto sexual- proferidos permanentemente por sus compañeros de partido o por sus rivales políticos. Este mismo patrón ha caracterizado el acceso de las mujeres a cargos públicos en todos los niveles. Las que lo han logrado - una minoría en relación al grueso de la población femenina-, primero, han tenido que competir desigualmente con hombres; segundo, han tenido que vencer prejuicios - muchas veces asumidos por ellas mismas - acerca de la superioridad y capacidad de los hombres; y tercero, una vez alcanzado un cargo público, han tenido que hacer frente a la resistencia tanto de sus subordinados a ser dirigidos por una mujer como de aquellos colegas que la rechazan como interlocutora, con iguales derechos y deberes que ellos.

En síntesis, la participación de las mujeres en la vida política y en cargos públicos se ve fuertemente limitada y socavada por la preeminencia y protagonismo de los hombres. Estos no sólo dominan en número la participación política y el ejercicio de cargos públicos, sino que positivamente - amparados en un marco de valores discriminatorios de la mujer- obstaculizan tanto su incorporación a la vida política y la formación de liderazgos femeninos como el acceso a $-y$ desempeño de ellas en-cargos públicos, sobre todo de los que tienen más relevancia en la administración gubernamental. ¿Están haciendo algo los partidos al respecto? ¿Se están tomando medidas para favorecer la participación de la mujer en la vida política?

En cuanto al problema de la participación de las mujeres en la vida política y en cargos de dirección partidaria, las medidas más sobresalientes tienen que ver con cambios en los estatutos de los partidos que permitan a las mujeres, por ejemplo, adquirir una cuota fija en los cargos de elección popular. El partido que más amplia y públicamente ha debatido este punto es el FMLN, cuyas militantes exigen que, por reglamento interno, se les reserve a ellas un porcentaje en las candidaturas para diputado. También se ha debatido el tema de otorgar permanentemente la candidatura de la vicepresidencia de la república a una mujer, mientras que un hombre sería el candidato a la presidencia. Hasta ahora, el debate no ha sido cerrado, siendo un tema pendiente en la agenda de discusión interna del FMLN tras las elecciones de marzo del 2000. Asimismo, el FMLN ha tomado medidas para garantizar la representatividad social de sus candidatos a alcaldes y concejos municipales: en su mayoría, esos candidatos se seleccionan entre los sectores mayoritarios de sus municipios, con lo cual se garantiza una más justa representación de esos sectores en esos cargos públicos. De algún modo, dadas las raíces sociales del FMLN, lograr una representatividad en los cargos públicos es una de las prioridades de este partido.

Partidos como ARENA, el PDC y el PCN, al menos públicamente, no parecen estar tomando medidas ni para favorecer la participación de las mujeres ni para lograr una mayor representatividad social en los cargos públicos. Sobre lo primero, más bien sucede lo contrario: en el caso de ARENA, poco a poco las mujeres del partido han ido siendo relegadas a un segundo plano en las decisiones más importantes. Han sido relegadas también de los cargos de dirección partidaria, los cuales van siendo ocupados por hombres. El PDC y el PCN, por su parte, no sólo son partidos dominados por hombres, sino que no se está haciendo nada para que eso cambie. Sobre lo segundo - la representatividad social de los cargos públicos-, ninguno de los tres partidos está tomando medidas para hacer que los intereses de los diversos grupos sociales se expresen en los cargos públicos. Desde estos partidos se promueve una "elitización" de la política, tras la cual lo únicos intereses que se ven represantados en los cargos públicos son los de la clase media y los de los grupos de poder económico.

Así pues, en El Salvador, el acceso a cargos públicos no es igual para todos los grupos sociales. Existe una discriminación de género que impide a las mujeres tener una mayor protagonismo en 
las decisiones del país. Esta es, pues, una gran fisura en la estructura social: los hombres controlan no sólo la mayor parte de cargos públicos, sino los más importantes: aquellos desde donde se deciden los destinos de El Salvador en materia social, económica y política. Ahora bien, no todos los hombres tienen iguales posibilidades de acceder a cargos públicos: el ámbito de selección privilegiado lo constituye la clase política, de entre cuyos miembros se seleccionan a quienes van a ocupar aquellos cargos de mayor relevancia pública.

Desde este punto de vista, son los miembros de los partidos los que mayores oportunidades tienen de acceder a cargos públicos: alcaldes, concejales, diputados, presidente de la república, ministros, presidente de la Corte Suprema de Justicia, etc. Pero no todos los miembros de los partidos pueden acceder por igual a todos los cargos públicos: sus dirigentes son los que más posibilidades tienen de acceder a aquellos más relevantes para la conducción del país. Ciertamente, hay partidos como el FMLN - y también el PAN-que cuentan entre sus mandos medios y mandos dirigentes a personas de extracción popular, lo cual favorece su acceso a cargos públicos (en el caso del FMLN, por ejemplo, al cargo de alcaldes y concejales). Pero, en el caso de otros partidos, esa situación es más bien excepcional.

Otro ámbito de selección lo constituyen los colegios de profesionales (de abogados, de economistas, de arquitectos) de donde se suelen seleccionar a no pocos funcionarios públicos. En su mayoría, tanto quienes integran la clase política como los colegios de profesionales, provienen de la clase media ilustrada, que se convierte, así, en la fuente que nutre de cuadros de dirección a la administración pública. Entonces, un carididato a ocupar cargos de dirección pública tiene que contar, como punto de partida, con el doble requisito de ser de la clase media ilustrada y de estar vinculado o bien a la clase política (como miembro de la dirigencia de un partido) o bien a un colegio profesional que ofrezca respaldo y relaciones con los círculos de poder económico y político. También los cargos públicos pueden ser ocupados por personas independientes, es decir, no vinculadas a algún partido o a alguna asociación profesional. Sin embargo, esas personas independientes, por lo general, están adscritas, por su educación y su estilo de vida, a la clase media.

En resumen, la participación política de los ciudadanos acusa en El Salvador de los años noventa unos niveles sumamente bajos. Por un lado, la sociedad civil muestra una notable escasez de organizaciones intermedias que expresen los diversos intereses y necesidades que se generan en su seno. Quizás el miedo por lo sucedido en el pasado pese en la decisión personal por pertenecer algún tipo de organización. También quizás estén pesando el conformismo con lo ya logrado en el país con los acuerdos de paz y la desconfianza en las instituciones y en la capacidad de estas para responder a los problemas de los ciudadanos.

Por otro lado, los diversos grupos sociales sobre todo los mayoritarios, compuestos por campesinos, obreros, desempleados y mujeres- no se sienten representados en los cargos públicos más importantes, siendo los sectores medios los que mayor representación tienen, al igual que los grupos de poder económico. Los que menos representación tienen son las mujeres y la población rural. Asimismo, fuera del ámbito político, son casi inexistentes las iniciativas -educativas y de capacitación- orientadas a fomentar y favorecer la participación política de las mujeres, incluso en aquellos organismos no gubernamentales dedicados a abordar los problemas de género. Tampoco por parte de la sociedad civil se están implementando medidas para favorecer la representación social en los cargos públicos, lo cual se traduce en bajos niveles de apoyo social a las iniciativas que puedan surgir con el objetivo de cambiar los dinamismos sociopolíticos predominantes. La contrapartida de lo anterior es la apatía ciudadana, su retirada del espacio público. Eso, a su vez, impide que la sociedad pueda ejercer presión sobre los partidos o que se puedan poner en marcha mecanismos de participación política alternativos a los meramente partidarios.

Luis Armando González 31 de mayo de 2000. 